\title{
6D AND $6^{18} \mathrm{O}$ IN SOUTH POLE SNOW: FURTHER COMPARISON \\ WITH METEOROLOGICAL DATA AND THE RECORD FROM THE LAST MILLENNIUM
}

\author{
(Abstract) \\ by \\ J.R. Petit***, J. Jouzel **, J.C. White *****, Qian Qiu-yu ******, M. Legrand * \\ and \\ M. Pourchet * \\ * (Laboratoire de Glaciologie et Géophysique de l'Environnement du C.N.R.S., \\ B.P. 96, 38402 St Martin d'Hères Cédex, France) \\ ** (Laboratoire de Géochimie Isotopique / LODYC, CEA/IRDI/DESICP, \\ DPC-CEN Saclay, 91191 Gif sur Yvette Cédex, France) \\ *** (Geochemistry Department, Lamont Doherty Geological Observatory, Palisades, NY 10964, U.S.A.) \\ **** (Department of Chemistry, Peking University, Beijing, People's Republic of China)
}

\begin{abstract}
The stable-isotope content of precipitation ( $\delta \mathrm{D}$ and $\left.\delta^{18} \mathrm{O}\right)$ is governed by the successive fractionation processes which occur during the atmospheric water cycle. As a result there is, in polar areas, a well-obeyed and theoretically well-understood linear relationship between the mean istopic content of snow and its mean temperature of formation. This relationship is well documented on a spatial scale but poorly known for a given site on a temporal basis, the main reason being that relatively long-term and sufficiently detailed meteorological data are only available for a few polar sites. The South Pole appears to be a suitable place for such a study because: (i) snow accumulation is high enough $(\sim 20 \mathrm{~cm}$ of snow per year), thus reducing the possibility that annual layers will be lost as a result of wind; (ii) seasonal variation in isotope content is still
\end{abstract}

preserved in snow up to 50 years old; (iii) meteorological data are available from the time the station was opened in 1957.

Our previous studies of surface and recently deposited snow at the South Pole were very encouraging in this respect; they have been extended with a two-fold purpose: (i) to test the geographical representativity of the isotope record by comparing results from various cores taken within a $10 \mathrm{~km}$ radius of the station. The cores are dated by various techniques, such as stratigraphy, seasonal variation in isotopic content, beta-radioactivity fall-out layers, and detection by solid conductivity measurements of the high "spike" which is thought to correspond to the 1815 Tambora eruption; (ii) to discuss the South Pole isotope record over the last 1000 years as recovered from a $127 \mathrm{~m}$ deep ice core. 